\title{
The parental care behaviour of Paratilapia polleni (Perciformes, Labroidei), a phylogenetically primitive cichlid from Madagascar, with a discussion of the evolution of maternal care in the family Cichlidae
}

\author{
Melanie L.J. Stiassny ${ }^{1} \&$ Cynthia L. Gerstner ${ }^{2}$ \\ ${ }^{\prime}$ Department of Herpetology and Ichthyology, American Museum of Natural History, New York, NY 10024, \\ U.S.A. \\ ${ }^{2}$ Current address: School of Natural Resources, University of Michigan, Ann Arbor, MI 48104, U.S.A.
}

Received 18.4.1991 Accepted 3.6.1991

Key words: Phylogeny, Madagascan endemic, Egg structure, Behaviour, Evolution

\section{Synopsis}

The parental behaviour of the Madagascan cichlid, Paratilapia polleni, was studied in the laboratory. According to current hypotheses of phylogenetic intrarelationship for the family Cichlidae, Paratilapia is a representative of a phylogenetically primitive cichlid lineage, and as such is of particular interest in comparative evolutionary studies. Given the basal phylogenetic placement of Paratilapia it seems reasonable to expect that, if maternal participation in brood care arose within the extant Cichlidae, then the proposed plesiomorphic system of extensive male care of eggs and embryos may be retained in this taxon. This is not the case, and already by the fertilized-egg interval male and female roles in Paratilapia are strongly differentiated with the female as the primary care giver. In addition to specialized behavioural roles, a unique egg morphology and mobile egg mass is described for Paratilapia. The results of the study are discussed in the context of theorics of the cvolution of maternal brood care within the Cichlidae.

\section{Introduction}

Cichlid fishes are noteworthy not only for their rapid taxonomic and morphological evolution (Echelle \& Kornfield 1984, Meyer et al. 1990, Stiassny 1991), but also for an array of specialized ecological and behavioural traits (Fryer \& Iles 1972, Keenleyside 1979, 1991, Loiselle 1985). Perhaps not surprisingly in view of this, cichlids exhibit a wide array of reproductive and parental care styles, ranging from bi-parental nest spawning and guarding to paternal, or more commonly, maternal (uni-parental) mouthbrooding (Breder \& Rosen 1966, Noakes \& Balon 1982). Unusually among care-providing teleosts, female cichlids adopt a ma- jor role in parental care, often to the exclusion of the male (Keenleyside 1979, Blumer 1982). Since the ground breaking study of Baerends \& Baerends van Roon (1950) there has been a considerable advance in our knowledge of the basic reproductive patterns of cichlid fishes (e.g. Fryer 1959, Wickler 1967, Barlow 1974, Noakes \& Balon 1982, Keenleyside 1979, 1991, Baerends 1984). Yet while many studies have aimed at an understanding of the evolution of parental care styles of cichlid fishes, attempts have been hindered by the lack of a broad phylogenetic context within which the disparate behavioural data could be situated.

While we are far from a detailed understanding of the precise interrelationships of the various ci- 


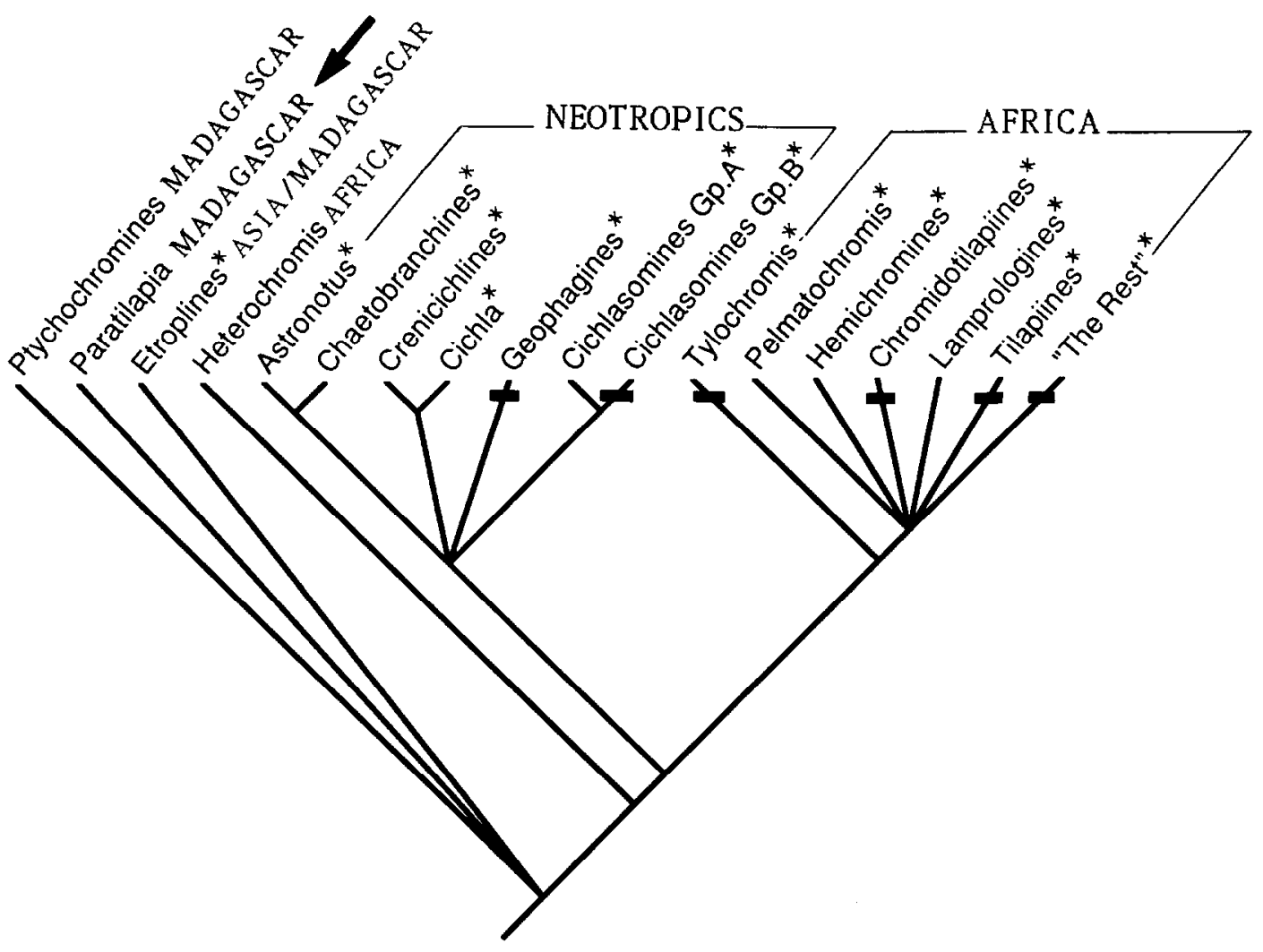

Fig. 1. Hypothesis of intrarelationships for the family Cichlidac. For a list of genera included in each named lineage, and characters defining the various assemblages see Stiassny (1987, 1990b, 1991). Asterisks indicate literature available on breeding biology of members within the starred lineages. Black cross-bars indicate lineages in which the occurrence of mouth brooding has been documented.

chlid lineages (Stiassny 1991), at least at the more inclusive levels, an hypothesis of relationship is now available. An overview of the phylogenetic intrarelationships of the major cichlid lineages and their geographical distributions is presented in Figure 1 . When our basic knowledge of reproductive patterns are mapped onto this scheme (indicated by ${ }^{*}$ in Fig. 1) it is evident that, with the notable exception of studies of the Asian genus Etroplus, (e.g. Barlow 1970, Cole \& Ward 1969, Rechten 1980a) data on cichlid reproduction and parental care have been derived exclusively from studies of phylogenetically advanced Neotropical and African taxa.

While we know nothing of the direct ancestry of the family (Stiassny \& Jensen 1987), as Figure 1 indicates, in the Madagascan taxa we have representatives of the most phylogenetically basal of the cichlid lineage(s). Clearly, these taxa occupy an important position with respect to the rest of the family and provide a unique resource for baseline studies; an analysis of the reproduction and parental care styles of these basal lineages provides the potential to begin to understand the temporal sequence of acquisition, and the role of reproductive diversification within the family as a whole (Stiassny 1992).

Prior to the present study virtually nothing was known of the reproductive biology of the Madagascan Cichlidae. What scant information does exist is contained in a single fisheries report (Kiener 1963), and an article published in an aquarium hobbyist journal (Catala 1977). Neither are detailed studies, and both do little more than establish the fact that the Madagascan Cichlidae are bi-parental substrate spawners. 


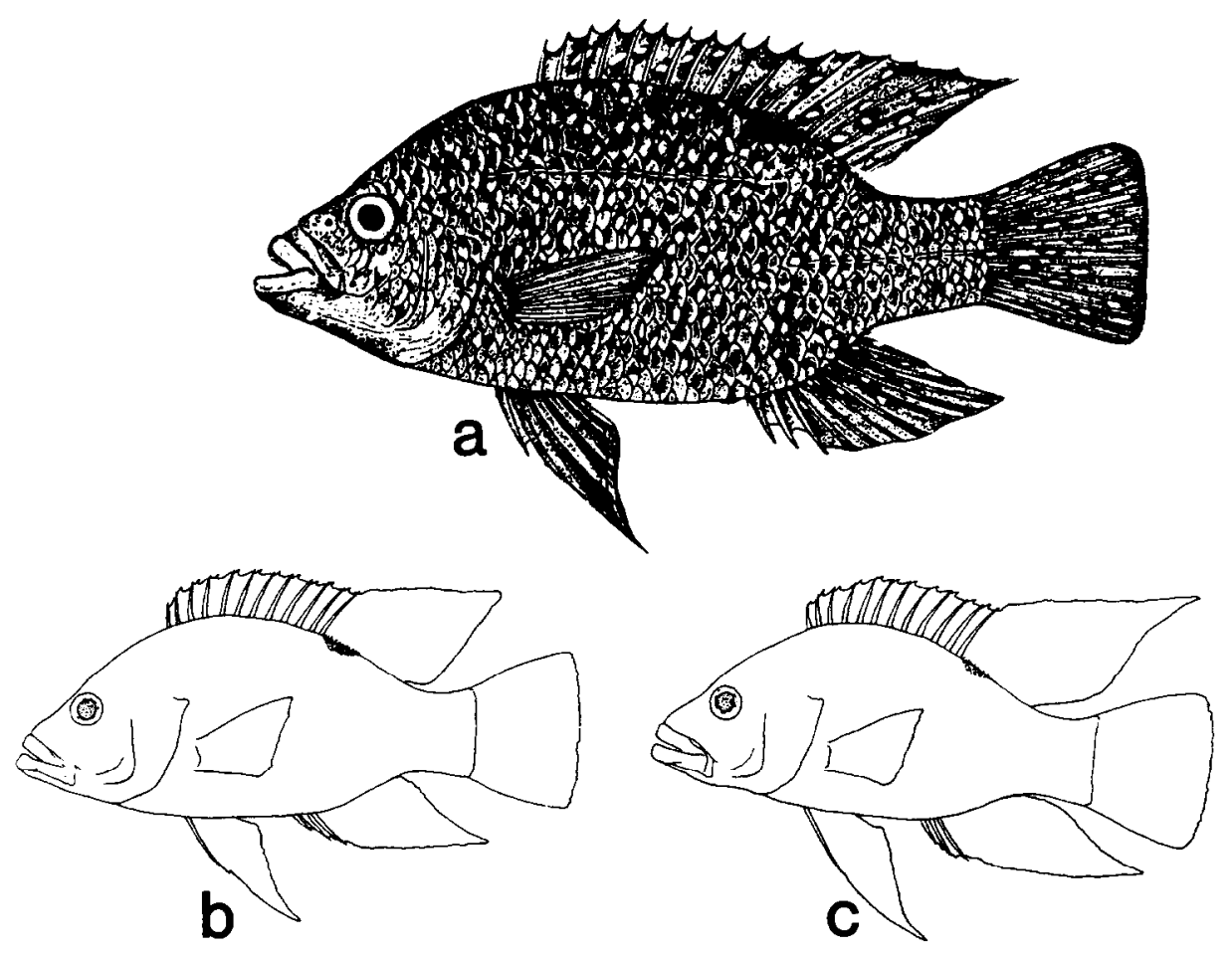

Fig. 2. Paratilapia polleni: a-General habitus and body pigmentation of a reproductively active female (modified after Kiener 1963). Outline drawings of adults, $b-$ female, $c$ - male.

Much of the reason for the dearth of information on the Madagascan Cichlidae results from the general unavailability of representative taxa (Loiselle 1985). Fortunately, a recent ichthyological survey of the fresh waters of the eastern highlands and coastal plain of Madagascar (Reinthal \& Stiassny 1991) has made a number of species available for study. This paper reports observations on the successful captive spawning of one of these species, Paratilapia polleni Bleeker, 1868.

\section{Notes on the biology of Paratilapia polleni}

The endemic Madagascan genus Paratilapia contains a single species, $P$. polleni (Kiener \& Maugé 1966). Prior to the extensive deforestation of much of the island, this species ranged more-or-less throughout Madagascan freshwaters (Kiener 1963). Today the species has a severely restricted distribution, and has been displaced over much of its former range by the introduction of a number of exotic species, most noteably the large-mouth bass, Micropterus salmoides, and the snakehead, Ophiocephalus striatus (Raminosoa 1987, Reinthal \& Stiassny 1991). The combined effects of habitat degradation and exotic species introductions has had a dire impact on the freshwater Madagascan ichthyofauna, and extinctions of endemic taxa have already been recorded (Stiassny 1990a, Reinthal \& Stiassny 1991).

Paratilapia is capable of surviving in a wide variety of habitats, water temperatures and chemistry. The species does not survive at temperatures lower than $12^{\circ}-15^{\circ} \mathrm{C}$ and is therefore excluded from land much above $1500 \mathrm{~m}$ (Kiener 1963), but is able to thrive in the small soda lakes in the south of the island where temperatures of $40^{\circ} \mathrm{C}$ are commonly encountered (Catala 1977). Paratilapia is rarely encountered in large numbers in fish catches and appears to be a more-or-less solitary species, although juveniles occur in aggregates (Stiassny personal observation).

Despite the large-mouthed, distinctly predatory 
facies of the species (Fig. 2), Paratilapia have a mixed diet of insects and aquatic larvae, crustaceans, tadpoles, small frogs and, occasionally, small fish (Kiener 1963, Stiassny personal observation). Growth is relatively slow and usually three years are required for specimens to attain lengths of about $25 \mathrm{~cm}$. The maximum recorded size for the species is a little in excess of $30 \mathrm{~cm}$. Paratilapia are sexually mature at a small size; $12 \mathrm{~cm}$ on the central plateau, and $8 \mathrm{~cm}$ in the nutrient poor acid waters of the coastal plain where growth rates are retarded (Kiener 1963). Sexual dimorphism is muted (Fig. 2), but males often have longer soft dorsal and anal fins, and during reproductive activity the male is frequently more vividly blackened with a more strongly contrasted blue spangling than the female whose ground colour is usually olive-brown with some golden and blue spangling on the flanks. Females also tend to be slightly deeper-bodied than males of equal size. Juveniles often display a series of dark vertical bands along the flanks, and have a typically occllatcd tilapia-spot (Thys 1968) on the soft dorsal fin. Interestingly, with growth the tilapia-spot migrates down from the soft dorsal to a definitive position on the dorsum of the body by lengths of about $30 \mathrm{~mm} \mathrm{SL}$. This pelmatochromisspot (Thys 1968) is retained in adult fish (Fig. 2).

Spawning takes place in the warm season (October-March) and pairs often mate several times with a spawning peak in November (Kiener 1963). According to Kiener (op. cit.) eggs are laid in a simple nest or in aquatic vegetation, where they are guarded without interruption by both parents; incubation lasts about 10 days at $22^{\circ} \mathrm{C}$. Catala (1977, p. 32) maintains that Paratilapia spawns in a nest 10 $20 \mathrm{~cm}$ diameter in a simple pit $30-40 \mathrm{~cm}$ in diameter where they have no protection other than the vigilant solicitude of the male and the constant attention of the female to aerate the eggs by movements of her pectoral fins (our translation). Catala (1977) claims that hatching takes place after 20 days, but does not specify the water temperature. Neither authors make any mention of egg morphology although Kiener (1963) notes that on average 800900 eggs are laid at first spawning to 3500 eggs by the second spawning of large females. Catala (1977) gives an estimate of about 1000 eggs as a normal clutch size. Our laboratory based observations accord well with these field data. However, we did note one anomaly; in all laboratory spawnings embryos were free of egg envelopes after only two days, rather than the extended period of 10-20 days cited by Kiener (1963) and Catala (1977). Laboratory water temperatures $\left(28-30^{\circ} \mathrm{C}\right)$ were somewhat elevated when compared with Kiener's (1963) record at $22^{\circ} \mathrm{C}$ and this may account for the truncated developmental period although an incubation period of two days is standard for most substrate spawning cichlids (Breder \& Rosen 1966).

\section{Materials and methods}

Juvenile Paratilapia polleni (10-20 mm SL) were collected in June 1988 by seine net in a large baylake (ca. $300 \mathrm{~m} \times 100 \mathrm{~m}$ ) by Salehy Village $\left(48^{\circ} 50^{\prime} \mathrm{E}, 19^{\circ} 55^{\prime} \mathrm{S}\right.$; altitude ca. $\left.10 \mathrm{~m}\right)$. The lake is situated inland of the first coastal dunc, $1 \mathrm{~km}$ south of the turn-off from Maralambo-Manajary road and is ringed by trees and coastal shrub vegetation, with some local disturbance and agriculture. Lake water is fresh, and turbid over the mud and sand bottom, in deeper water the lake floor was strewn with tree trunks and branches. The maximum depth of water is little more than $4 \mathrm{~m}$. Water temperature was approximately $28^{\circ} \mathrm{C}$.

The Paratilapia juveniles were collected in shallow water at the lake's edge by Salehy village, where they occurred in sympatry with Ptychochromis oligacanthus juveniles, Tilapia zillii juveniles (introduced species), Sauvagella madagascariensis and Teramulus kieneri (Reinthal \& Stiassny 1991). Voucher specimens of Paratilapia polleni collected at this locality are housed in the collections of the American Museum of Natural History (AMNH 88101).

Despite intensive collecting efforts (seine, hook and line and trawling), and underwater observations (snorkeling) no adult Paratilapia were observed in the lake, although as no large inflowing streams were present it is assumed that the parental fish were present. On a return visit to the Salehy Lake in September 1990 additional juvenile Para- 
tilapia were collected, but again no adults were observed. It is possible that local fishermen are selectively removing the larger specimens from the lake.

The 1988 collection was transported to the American Museum and raised in holding tanks maintained at $28^{\circ}-30^{\circ} \mathrm{C}$. The fish were fed twice daily on a mixed diet of commercial flake (Tetramin), frozen Tubifex, and commercial pellets (Doromin).

On June 18, 1990 five individuals (two males, $16.5,15.2 \mathrm{~cm} \mathrm{SL}$, and three females, $10.5,12.0$ and $12.9 \mathrm{~cm} \mathrm{SL}$ ) were placed into a wooden octagonal tank $(2 \times 1.5 \mathrm{~m})$. The bottom of the tub was covered with $6 \mathrm{~cm}$ of aquarium gravel and fine sand, and supplied with rock caves, ceramic pots, slate and submerged drift wood providing hiding and spawning sites. After two days a pair had formed (male $16.5 \mathrm{~cm} \mathrm{SL}$, female $10.5 \mathrm{~cm} \mathrm{SL}$ ) and the remaining fish were removed. On June 27, two individuals (male $15.2 \mathrm{~cm} \mathrm{SL}$, and female $12.9 \mathrm{~cm} \mathrm{SL}$ ) were reintroduced to the tank, but separated from the paired couple, and from each other, by wire mesh barriers. The tank water was slightly brackish, with a $\mathrm{pH}$ value of 7.5-8.0 (1 heaped teaspoon of commercial brand non-iodised table salt added per 501 ). Water temperature was maintained between $28-30^{\circ} \mathrm{C}$, and the fish were fed twice daily on a diet of frozen Tubifex worms, live meal worms and Doromin pellets. In addition to natural daylight, artificial fluorescent light was given from 700 to $1900 \mathrm{~h}$.

The first spawning of this pair occurred on 18 July 1990, behaviour was observed and after two weeks the free-swimming larvae were removed. At the second spawning of the pair on 14 August videotaping commenced and continued until $26 \mathrm{Au}$ gust. Recordings were taken for five minute intervals each daylight hour, and focal sampling video records were made with minimal disturbance to the fish. Sequences were transcribed to data sheets and each behaviour of the pair was recorded. If an activity was discontinued, but immediately resumed, it was counted as a separate occurrence. The duration of behaviours was not recorded. The quantitatively followed sequence is of the second spawning of the pair. Qualitative descriptions of courtship, spawning and parental care are from the first and second spawnings.

The following behavioural action patterns were observed and recorded for analysis. Descriptions have been modified after several authors (e.g. Baerends \& Baerends van Roon 1950, Baerends 1984), and are stated here for clarity:

Chafe $(\mathrm{CF})=$ swim rapidly towards the substrate or side of the tank, scraping the sides of the body.

* Charge $(\mathrm{CH})=$ rapidly approach conspecific with spread opercula and extended branchiostegal membranes.

Clear $(C)=$ extensive opening of mouth.

${ }^{*}$ Dig $(\mathrm{DG})=$ remove a mouthful of gravel.

Eat $(E T)=$ pick-up a mouthful of food from the substrate.

* Fan $(\mathrm{FN})=$ fanning of pectoral and caudal fins over egg mass.

Mouth fight $(\mathrm{MF})=$ two opponents attempt to grasp one another by the mouth, pushing and pulling (incomplete due to presence of mesh barrier).

${ }^{*}$ Guard $(\mathrm{GU})=$ standing (defending if necessary) within one body length of egg mass, free embryos and free-swimming larvae.

* Nip (NP) = pick-up individual pieces of gravel from the brooding pit, clean and spit out.

${ }^{*}$ Pick-up young $(\mathrm{PY})=$ pick-up stray embryos or larvae and spit them back into the group.

* Shovel $(\mathrm{SH})=$ remove a mouthful of gravel and transport one or two body lengths with characteristic caudal undulations and pectoral fanning.

* Threat (TH) $=$ spread opercula and extend branchiostegal membranes at conspecific.

Because of the limited number of fish available for study, our spawning and parental care data represent repeated observations of a single pair of Paratilapia. Therefore, we present here an exploratory analysis (Martin \& Bateson 1986), and summarise our data in the form of standard transition diagrams (Fig. 3) and mean daily frequency graphs (Fig. 4).

Sequence analysis contingency tables were generated in absolute frequency numbers for male and female behavioural categories at the fertilized-egg (embryo), free-embryo (= wriggler), and free- 


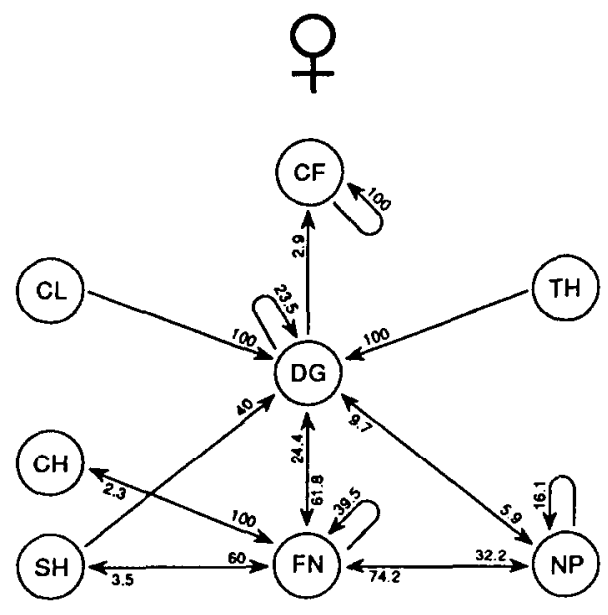

Egg

$\sigma^{\prime \prime}$
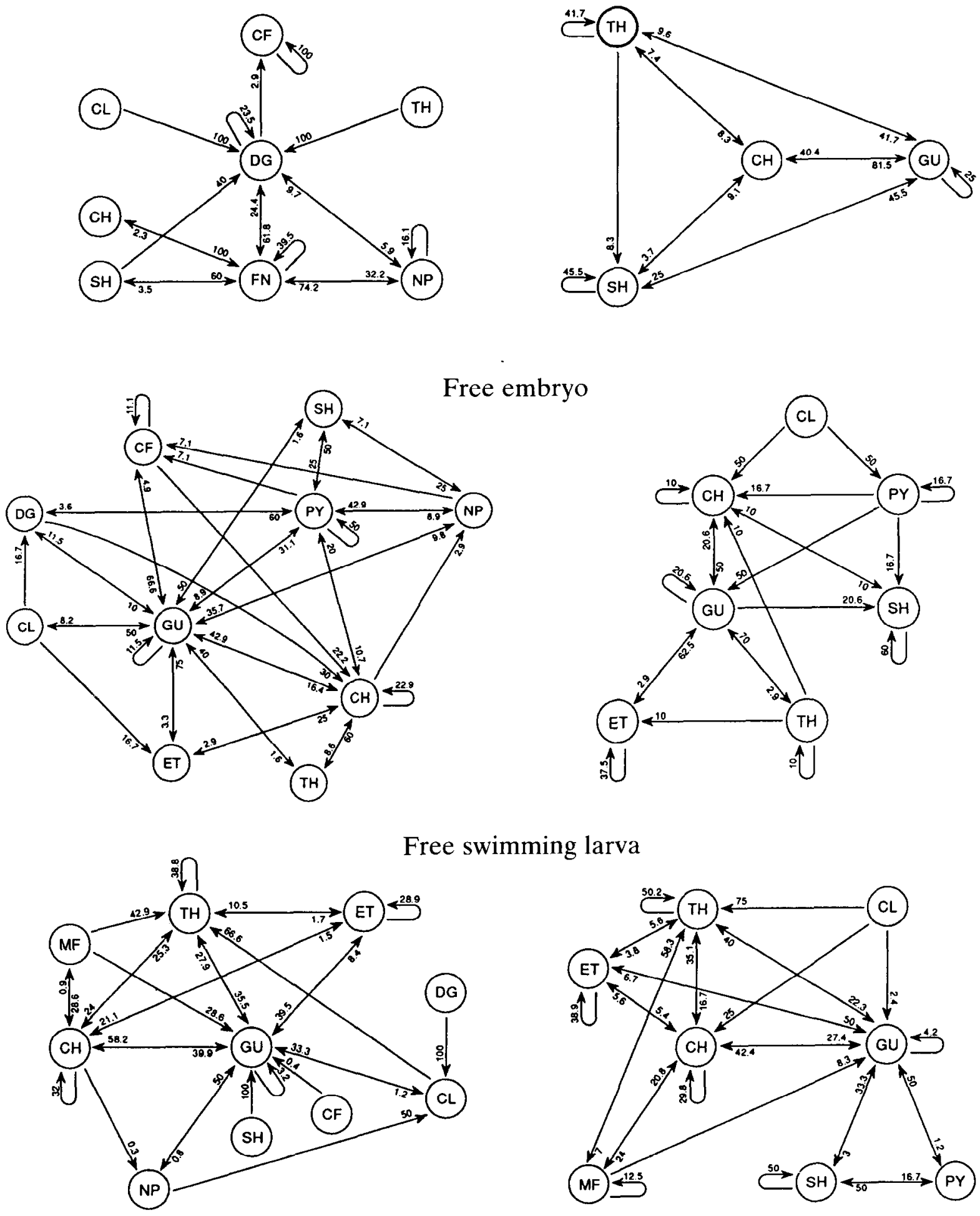
swimming larval stages (Balon 1975, 1984, 1990, Baerends 1984). The matrices were constructed with diagonals, since we were interested in all transitions occurring (Perrone 1978). All behavioural transitions are physically possible, and behavioural transition sequence diagrams were constructed for each parental care interval (Fig. 3).

Parental care behaviour (marked with an asterisk $^{*}$ ) was compared to chart differential male and female frequencies of response. Graphs were constructed comparing the mean daily frequencies (in absolute numbers) of the parental care behaviour for each of the five minute observation periods (Fig. 4).

\section{Results}

\section{Qualitative description of reproductive behaviour}

\section{Courtship and spawning}

Prior to spawning the male Paratilapia actively courted the female. The male fish developed a spectacular black breeding coloration with strongly contrasting light blue spangling on the flanks and soft dorsal fin. The male performed frequent 'body quivering' (Baerends \& Baerends van Roon 1950) bouts in front of the female, and these were intermixed with repeated shovelling behaviour which resulted in the creation of a brooding pit. The pit was a shallow depression approximately $10 \mathrm{~cm}$ in diameter excavated in the gravel in front of a ceramic cave which was open at both ends. As spawning approached, the female joined the male in shovelling and digging. On the day before spawning, both male and female became increasingly aggressive towards the two conspecifics on the other side of the barrier. On one occasion the male conspecific escaped into the pair's area. Mouth fighting and biting with the paired male ensued. After defeat, the intruding male was returned to his area behind the wire barrier. During this time the female remained olive-brown with pale golden spangling on the flanks, unless showing aggressive behaviours, in which case she rapidly flushed blackish-brown or fully black with some blue and brown spangling.

On the day of spawning the female was highly responsive to the male, quivering in front of him and maintaining a blackish coloration with some blue and brown spangling. Her digging and nipping became increasingly localised in the brooding pit and inside the ceramic cave. At $1100 \mathrm{~h}$ the short, conical genital papilla of the female had fully descended. Spawning occurred at approximately $1430 \mathrm{~h}$, with the female remaining inside the ceramic cave for most of the time. The male circled around and through the cave repeatedly, presumably inseminating the ova as the female extruded a continuous egg string. The male's genital papilla was not visible externally. Egg extrusion and insemination were partially obscured from view by the cave walls.

\section{Egg structure}

After spawning was completed, the cave was overturned to expose the egg string. Individual eggs were not attached to the substrate, as is common with other substrate spawning cichlids (Breder \& Rosen 1966), but instead were connected to each other. From an adhesive central fiber bundle radiated thinner fiber bundles each attaching to a single egg (Fig. 5). About 1000 ovoid eggs were laid and each egg was transparent with an approximate diameter of $1 \mathrm{~mm}$. Through the fanning activities of the female, the central adhesive fiber bundle became intertwined with itself and the eggs pulled together into a dense egg mass three or four egg layers deep, with a surface area of about $6 \mathrm{~cm}^{2}$. The egg mass was not adherent to the substrate and was readily moveable by vigorous unilateral pectoral fanning by the female.

\section{Parental care}

The female alone fanned the egg mass, a central activity that occupied most of her time during this

\footnotetext{
Fig. 3. Positive behavioral transition diagrams of adult $P$. polleni during fertilized-egg, free-embryo, and larva stages. Numbers indicate the percentage transition to the following behaviour.
} 

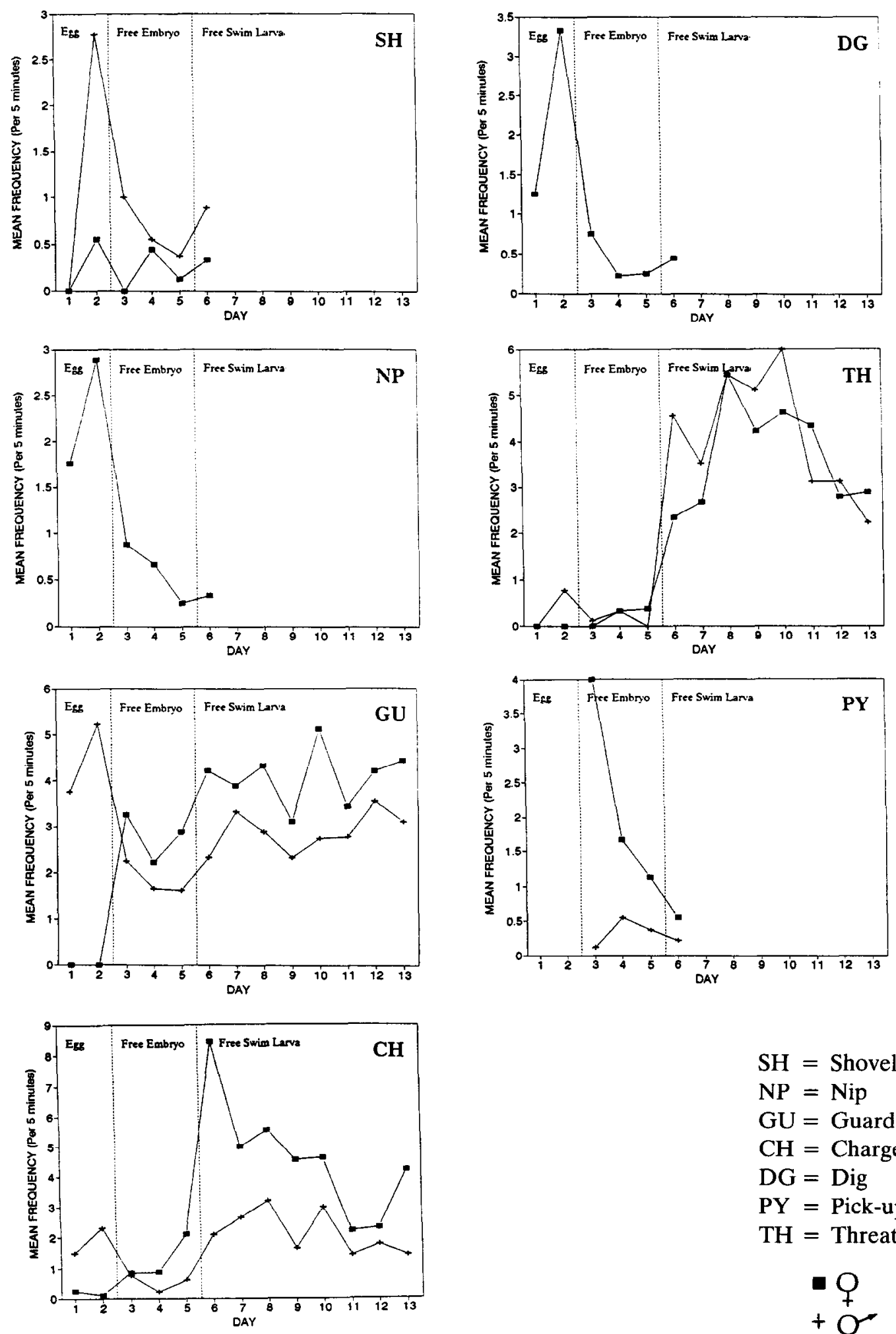

$$
\begin{aligned}
\mathrm{SH} & =\text { Shovel } \\
\mathrm{NP} & =\text { Nip } \\
\mathrm{GU} & =\text { Guard } \\
\mathrm{CH} & =\text { Charge } \\
\mathrm{DG} & =\text { Dig } \\
\mathrm{PY} & =\text { Pick-up young } \\
\mathrm{TH} & =\text { Threat } \\
& =\text { Q } \\
& +\mathrm{O}^{-}
\end{aligned}
$$

Fig. 4. Mean daily behaviour frequencies of $P$. polleni during egg, free-embryo, and larva stages. 
period. In fact, the female would occasionally charge the male if he approached too near to the mass. Since the egg mass was free from the substrate, the female was able to move it over short distances $(6-10 \mathrm{~cm})$ by unilateral fanning of her pectoral fins. The male maintained a position on the periphery of the brooding pit frequently charging and threatening the interested conspecifics at the barrier. He continued to deepen and expand the brooding pit until the depression was approximately $20 \mathrm{~cm}$ in diameter. The female rarely left the egg mass, and then only to dig-out a small area under a rock at the periphery of the brooding pit. When the female did leave the mass, the male moved in closer (one body length from the mass) and guarded it.

After two days the embryos had hatched and were free of their egg envelopes. This incubation duration is considerably shorter than that reported by Kiener (1963) or Catala (1977), but is typical for cichlid substrate spawners (Breder \& Rosen 1966). The attachment of the free embryos was on top of the gravel in the brooding pit, a few centimeters from the spawning site in the ceramic cave. Parental fish were not observed transferring the free embryos by mouth, nor was there any fanning of them. Light microscopic examination of $12 \mathrm{~h}$ old free embryos revealed head gland structure typical of substrate spawning cichlids (Jones 1972). During the free-embryo phase, parental care was limited to passive guarding and the picking-up of disattached embryos and spitting them back into the central group for reattachment. This was done primarily by the female, and occasionally, considerably more clumsily, by the male. The free embryos remained in the same location until free-swimming three days later.

During the free-swimming interval both parents travelled with the shoal of larvae, but did not appear to lead, and no obvious pelvic fin flickering (Cole \& Ward 1969, Baldaccini 1973) or jolting behaviours (Baylis 1974, Keenleyside 1979) were observed. As the days passed, the free-swimming shoal travelled together throughout the tank. As the shoal approached the wire barrier, the parents became increasingly agitated and aggressive towards the conspecific adults on the other side of the

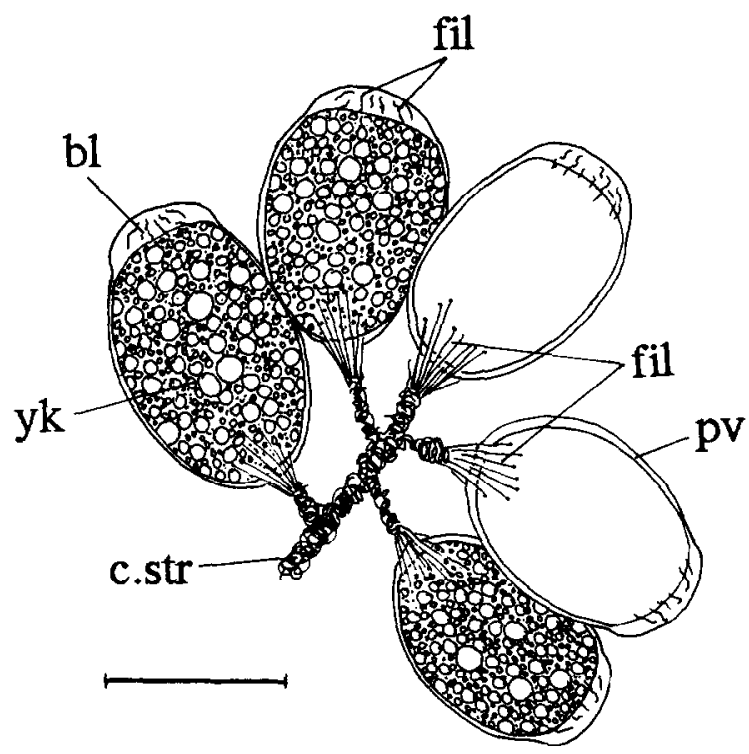

Fig. 5. Small portion of egg string of Paratilapia polleni four hours after insemination. Abbreviations: bl, blastoderm; c.str, central 'string'; fil, filaments; pv, perivitelline space; yk, yolk with dispersed lipoid globules. Scale bar indicates $1 \mathrm{~mm}$.

barrier. These responses included repeated charges and attempts at mouth-fighting. The female's defensive tactic was to charge and immediately return to the shoal, while the male often stayed at the barrier for longer periods of time. Except when aggressively interacting with conspecifics, the male's colouration was non-reproductive, being olive-brown with pale blue-brown spangling. At the onset of the free-swimming interval the female developed a vivid black ventral body and pelvic fin colouration which contrasted strongly with her now pale brown dorsal and lateral body colouration.

The young were removed after thirteen days since the parents were beginning to catch and eat straying individuals.

\section{Descriptive sequence transition analysis}

Figure 3 represents the behavioural transitions of male and female Paratilapia at the egg, free-embryo and swimming-larva developmental intervals of the offspring. Important transitions for the fe- 
male in the egg interval involved fanning behaviour. Fanning preceded digging and nipping, while it followed nipping, digging and charging. The male did not fan at all and important transitions involved charging preceding and following guarding, and shovelling leading to other bouts of shovelling and guarding.

Dominant female transitions at the free-embryo phase included several behaviours (guarding, nipping, digging, picking-up young) leading to picking-up young, or several (eating, charging, chafing) leading to guarding. For the male the dominant behaviour involved threat leading to guarding transition.

Differences in paternal transitions were virtually non-existent by the free-swimming larva period.

\section{Parental care data}

Parental care patterns are represented at three developmental phases (Fig. 4): fertilized egg, freeembryo and free-swimming larva. At the point of transition between the free-embryo and free-swimming larva stages the category containing the greatest proportion of the young was selected. Fanning, digging and nipping were only performed by the female. Charge was the most changeable behaviour. The male performed more charges at the egg phase, while the female fanned the egg mass. This changed during the free-embryo phase, such that by the free-swimming larva period the female performed more charges than the male. The female also performed more picking-up of young at the free-embryo phase and early in the first day of free-swimming. No guarding behaviour was recorded for the female during the egg phase since she was continuously occupied with fanning the egg mass, but she guarded more than the male during the free-embryo and free-swimming larva intervals. Shovelling was performed more often by the male during the egg phase but little difference was noted by the free-embryo and free-swimming larva intervals. Threat behaviours were not markedly different between male and female during any developmental interval.

\section{Discussion}

In the great majority of teleost families in which parental care has evolved, it is the male that is the primary, and usually exclusive, care giver (Breder \& Rosen 1966, Blumer 1982). Beyond courtship and spawning, females play little or no role in the care of their progeny. Cichlid fishes are therefore notable among care providing teleosts in that the female adopts a major, and often exclusive role in the parental care of embryos and free-swimming larvae. Attempts at explanation of this 'anomaly' are manifold (e.g. Barlow 1974, 1984, Baylis 1974, Perrone \& Zaret 1979, Noakes \& Balon 1982, Gross \& Sargent 1985). All make the reasonable assumption that the plesiomorphic state of biparental care arose (in cichlid ancestry) from a system of primary male care of eggs and embryos, with a gradual increase and ultimate usurpment of care provision by the femalc. Actually there is little evidence of a homologous transition in the parental behaviours in related labroid families (Kaufman \& Liem 1982, Stiassny \& Jensen 1987). The Labridae exhibit a general pattern of protogynous hermaphroditism with a polygynous social system (Barlow 1984) involving no parental care of eggs or embryos. The Embiotocidae are live bearers with fullterm internal gestation (Shaw 1971, Blumer 1982) and no parental care. The Pomacentridae exhibit a general pattern of exclusive male care of demersal eggs that hatch into pelagic embryos and larvae. Interestingly, one species of damsel fish, Acanthochromis polyacanthus, does engage in biparental care of free-swimming larvae in a manner resembling that of substrate-spawning cichlids (Robertson 1973, Barlow 1984). Maternal investment in the care of offspring appears to be an innovation of the family Cichlidae, and relevant outgroup data are not available to aid in understanding the evolutionary sequence of the origin of that behaviour within the family. In view of this, evidence for the proposed behavioural transition to maternal care in the Cichlidae must come from studies of cichlid species themselves.

Within the Cichlidae it is tempting to hypothesise an evolutionary sequence from species show- 
ing little differentiation in male and female roles (e.g. Etroplus maculatus, etropline: Cole \& Ward 1969; Pterophyllum scalare, cichlasomine Gp.A: Chien \& Salmon 1972), to systems in which the female provides somewhat more direct care of eggs and free-embryos than the male (e.g. Tilapia mariae, tilapiine: Baldaccini 1973; Herotilapia multispinosa, cichlasomine Gp.A: Smith-Grayton \& Keenleyside 1978), to almost exclusive maternal care of eggs and free-embryos (e.g. 'Cichlasoma' species, cichlasomine Gp.A: Barlow 1974; Boulengerochromis, 'the rest': Kuwamura 1986). The hypothesised endpoint of such a behavioural transition is the evolution of polygyny and ultimately maternal mouth brooding (Fryer \& Iles 1972, Peters \& Berns 1982). However, mapping this set of behavioural transitions onto a scheme of interrelationship for the various taxa (Fig. 1) reveals no sequential pattern of behaviour acquisition in these taxa. Studies within the Cichlidae do not appear to corroborate the hypothesised series of sequential behavioural modifications leading from primary male care, through increasing female participation, to primary care by females.

Nonetheless, given such a scenario and with no relevant outgroup data, it seems a reasonable expectation that in a phylogenetically primitive cichlid taxon such as Paratilapia, we may find evidence of the proposed plesiomorphic system of extensive male care of eggs and embryos, or at least muted sexual differentiation of roles. Interestingly this is not the case, and in Paratilapia polleni male and female roles are already strongly differentiated at the fertilized egg stages. The female is the primary care giver, even to the extent of chasing the male away if he approaches the embryos too closely. Similarly, fanning of the eggs is solely a female task. This represents a marked division of labor, similar to that of the Lake Tanganyikan endemic, Boulengerochromis microlepis, where the male would approach the nest and fertilized eggs if the female briefly left, but never exhibited fanning behaviour (Kuwamura 1986).

In the free-embryo and free-swimming larva stages, parental care behaviours are common to both sexes but differ quantitatively (Fig. 4). Con- trary to reports for many other cichlid species (e.g. Baerends \& Baerends van Roon 1950, Breder \& Rosen 1966, Keenleyside 1979), in Paratilapia polleni parental fanning does not continue into the free-embryo phase. In addition, parental fish were not observed transferring eggs or free-embryos from pit to pit. The only mouthing behaviour observed occurred when free-embryos were picked up (primarily by the female) and spat back into the group for reattachment. This is a noteworthy absence of a typical cichlid behaviour in Paratilapia, particularly as the mouthing and oral transfer of eggs and embryos by parental fish has been suggested as a transition behaviour or preadaptation for mouthbrooding (Fryer \& Iles 1972, Keenleyside 1979), a behaviour that has arisen independently at least three times within the family (Fig. 1, mouthbrooding occurs in lineages marked with black cross-bars).

At the free-embryo phase guarding is an important female behaviour, although other primary defensive behaviour such as charging shows no marked differences between the sexes. However, by the larva period the female performs more charges, often swiftly attacking the proximate intruder at the barrier, and quickly returning to the shoal of larvae. The male tends to remain at the barrier for longer periods, thus performing less charges. Itzkowitz \& Nyby (1982) have suggested that such an inequality may be due to the larger, more intimidating size of the male which allows for less defensive behaviour than in the smaller female (see also Fryer \& Iles 1972).

The differentiation of parental roles in Paratilapia at the larval stages contrasts with that of most other substrate-spawning cichlids where quantitative differences in male/female behaviour are all but negligible (e.g. Baerends \& Baerends van Roon 1950, Cole \& Ward 1969, Barlow 1974, Baylis 1974, Smith-Grayton \& Keenleyside 1978, Keenleyside 1979, Lavery et al. 1990). Further adding to the evidence of late differentiation of parental roles in Paratilapia is the development of a striking inverse counter-shading in the female at the onset of the free-swimming larva period. Inverse counter-shading has been reported for a 
number of reproductively active cichlid species (e.g. Herotilapia multispinosa: Baylis 1974; 'Cichlasoma' biocellatum: Baerends \& Baerends van Roon 1950; Etroplus maculatus: Rechten 1980), but in each of these cases both parents exhibited the colouration. Since only the female Paratilapia exhibits countershading it seems reasonable to assume that a further division of parental roles is occurring with respect to an unidentified maternal young interaction.

We are aware of the problems associated with aquarium-based behavioural studies (e.g. Fernald \& Hirata 1977, Rechten 1980a, b), and the caution needed when extrapolating their results to natural systems. However, based upon our observations it seems reasonable to conclude that if the proposed behavioural transition, from a primitive system of male care of eggs and embryos through increasing female participation of brood care to primary female care of eggs and young has occurred, its origination long predates the origin of the extant $\mathrm{Ci}$ chlidae. In living cichlids, instead of a sequential pattern of modification of parental care behaviour in progressively more phylogenetically derived cichlid clades we find a mosaic occurrence of seemingly comparable behavioural patterns in diverse lineages. At least at the levels considered here, a profound flexibility with multiple independent originations and/or reversals appears to be the dominant theme of behavioural evolution within the Cichlidae.

\section{Egg morphology}

It has been noted earlier that fanning of the eggs is solely a female activity, and during this time the female spends most of her time tending and fanning the egg mass. Although quantitative data are not yet available it appears that the high proportion of time that the Paratilapia female spend fanning the egg mass may be related to the peculiar threedimensional structure of the mass. The requirement of oxygenation of eggs in the middle of the mass may be a constraining factor limiting female activity to egg care and fanning.

Whatever the behavioural ramifications may be, a major difference between Paratilapia and all other substrate spawning cichlids is evident in the morphology of the eggs and in the presence of a mobile egg mass (Stiassny et al. unpublished). Typically during the maturation of the eggs of substrate spawning cichlids, the zona radiata of the oocyte is covered by a chorion with a profusion of fine adhesive filaments, and glutinous secretions are adhered to the egg surface before it is laid (Kraft \& Peters 1963, Fryer \& Iles 1972). The eggs are oviposited individually and are adhered to the substrate by the sticky mucous coating and/or adhesive filaments (Wickler 1956, Breder \& Rosen 1966). At points of contact between eggs, egg to egg attachment is facilitated by the mucous coating and fine filamentous threads (Kraft \& Peters 1963). Eggs usually adhere to the substrate in a single layered egg plaque (Greenberg et al. 1965, Loiselle 1985 , Ostrander \& Ward 1985), although in at least one species, Boulengerochromis microlepis, the egg plaque may be up to three egg layers deep. Interestingly, in this species it is the female alone that fans the egg mass (Kuwamura 1986).

With respect to cgg morphology, the situation in Paratilapia differs radically from that of other cichlid species. As is illustrated in Figure 5, Paratilapia eggs are attached to one another by a central adhesive filament string. Smaller filament bundles branch off the central string and attach to individual eggs. The initial fanning activities of the female tangles the central string causing the individual egg filament bundles to become intertwined with the central string and with one another pulling the individual eggs into a dense mass three or four eggs deep. At all times the egg mass remains free from the substrate and is readily moved by vigorous unilateral pectoral fanning by the femalc. Although the egg mass was rarely moved distances greater than $5-10 \mathrm{~cm}$, fanning manipulations of the female facilitated effective temporary concealment of the eggs beneath and between rock crevices.

Moveable egg plaques have been described for some other cichlid species (e.g. Geophagus jurupa$r i$, Cichocki 1976; Aequidens paraguayensis and Ae. coeruleopunctatus, Timms \& Keenleyside 1975). However, these systems involve the deposition of the egg plaque onto a disattached leaf which is then dragged to different locations by the parent fish. While seemingly providing a functionally 
analogous mobile nest, this loose leaf system involves no morphological specialization of the eggs themselves.

The morphological features of egg structure in Paratilapia are unique among cichlids (and other perciforms) studied to date, and undoubtedly represent an evolutionary specialization of the clade. In this regard, information on the egg morphology of the remaining Madagascan Cichlidae is highly desirable, and may prove to be of some importance in future studies of the phylogenetic intrarelationships of these basal cichlid lineages (Stiassny 1991).

In view of the paucity of information on the reproductive biology of the evolutionarily important cichlid fauna of Madagascar we hope that this preliminary study provides a starting point for future work, and will act as an incentive for continued efforts at gathering critical field observations.

\section{Acknowledgements}

Our thanks go to Paul Loiselle and Peter Reinthal for their many helpful comments, insights and suggestions made during the course of this study. Thanks also to Claudia Bestor whose initial work with the Paratilapia juveniles laid the foundation for the current project. For logistical support during the 1988 and 1990 collecting expeditions to Madagascar, we are most grateful to the Department of Water and Forests, Antananarivo, to Pat Wright and Peter Reinthal. Niel Landman kindly helped with the French translation of a number of important papers. For many helpful comments on earlier drafts of this paper we thank Peter Moller and Eugene Balon. This work was supported by NSF Research Experience for Undergraduates (REU) Site Awards to the senior author. Funding from the NSF REU awards supported the Summer research of Claudia Bestor (DIR 8900580) and Cynthia Gerstner (DIR 9001058).

\section{References cited}

Baerends, G.P. 1984. The organization of pre-spawning beha- viour in the cichlid fish Aequidens portalegrensis (Hensel). Neth. J. Zool. 34: 233-366.

Bacrends, G.P. \& J.M. Bacrends van Roon. 1950. An introduction to the study of the ethology of cichlid fishes. Behaviour Suppl. 1: 1-242.

Baldaccini, N.E. 1973. An ethological study of reproductive behaviour including the colour patterns of the cichlid fish Tilapia mariae (Boulenger). Monit. Zool. Ital. 7: 247-290.

Balon, E.K. 1975. Reproductive guilds in fishes: a proposal and definition. J. Fish. Res. Board Can. 32: 821-864.

Balon, E.K. 1984. Reflections on some decisive events in the early life of fishes. Trans. Amer. Fish. Soc. 113: 178-185.

Balon, E.K. 1990. Epigenesis of an epigeneticist: the development of some alternative concepts on the early ontogeny and evolution of fishes. Guelph Ichthyol. Rev. 1: 1-48.

Barlow, G. 1970. A test of appeasement and arousal hypotheses of courtship behavior in a cichlid fish, Etroplus maculatus. Z. Tierpsychol. 27: 779-806.

Barlow, G. 1974. Contrasts in social behavior between Central American cichlid fishes and coral reef surgeon fishes. Amer. 7ool. 14: 9-34

Barlow, G. 1984. Patterns of monogamy among teleost fishes. Arch. FischWiss. 35: 75-123.

Baylis, J.R. 1974. The behaviour and ecology of Herotilapia multispinosa (Teleostei, Cichlidae). Z. Tierpsychol. 34: 115146.

Baylis, J.R. 1981. The evolution of parental care in fishes, with reference to Darwin's rule of male sexual selection. Env. Biol. Fish. 6: 223 251.

Blumer, L.S. 1982. A bibliography and categorization of bony fishes exhibiting parental care. Zool. J. Linn. Soc. 76: 1-22.

Breder, C.M. Jr. \& D.E. Rosen. 1966. Modes of reproduction in fishes. T.F.H. Publications, Neptune City. 941 pp.

Catala, R. 1977. Poissons d'eau douce de Madagascar par René Catala (suite). Rev. fr. Aquariol. 1: 27-32.

Cichocki, F.P. 1976. Cladistic history of cichlid fishes and reproductive strategies of the American genera Acarichthys, Biotodoma and Geophagus. Ph.D. Thesis, The University of Michigan, Ann Arbor. 705 pp.

Chien, A.K. \& M.S. Salmon. 1972. Reproductive behavior of the angelfish Pterophyllum scalare. I. A quantitative analysis of spawning and parental behavior. Forma et Functio 5: 45 74.

Cole, J.E. \& J.A. Ward. 1969. The communication function of pelvic fin-flickering in Etroplus maculatus (Pisces: Cichlidae). Behaviour 35: 179-199.

Echelle, A.A. \& I. Kornfield. 1984. Evolution of fish species flocks. University of Maine Press, Orono. $257 \mathrm{pp}$.

Fernald, R.D. \& N.R. Hirata. 1977. Field study of Haplochromis burtoni: quantitative behavioural observations. Anim. Behav. 25: 964-975.

Fryer, G. 1959. The trophic interrelationships and ecology of some littoral communities of Lake Nyasa with especial reference to the fishes, and a discussion of the evolution of a group of rock-frequenting Cichlidae. Proc. Zool. Soc. Lond. 132: 153-281. 
Fryer, G. \& T.D. Iles. 1972. The cichlid fishes of the Great Lakes of Africa. Their biology and evolution. Oliver and Boyd, Edinburgh. 641 pp.

Greenberg, B., J.J. Zijlstra \& G.P. Baerends. 1965. A quantitative description of the behaviour changes during the reproductive cycle of the cichlid fish Aequidens portalegrensis Hensel. Koninkl. Nederl. Akad. Wet. Series C, 68: 135-149.

Gross, M.R. \& R.C. Sargent. 1985. The evolution of male and female parental care in fishes. Amer. Zool. 25: 807-822.

Itzkowitz, M. \& J. Nyby. 1982. Field observations of parental behavior of the Texas cichlid, Cichlasoma cyanoguttatum. Amer. Midl. Nat. 108: 364-368.

Jones, A.J. 1972. The early development of substrate brooding cichlids (Teleostei: Cichlidae) with a discussion of a new system of staging. J. Morph. 136: 255-272.

Kaufman, L. \& K.F. Liem. 1982. Fishes of the suborder Labroidei (Pisces, Perciformes): phylogeny, ecology and evolutionary significance. Breviora. Museum of Comparative Zoology, Harvard University 472: 1-19.

Keenleyside, M.H.A. 1979. Diversity and adaptation in fish hehaviour. 7oophysiology, Vol. 11, Springer-Verlag, Heidelberg. 208 pp.

Keenleyside, M.H.A. 1991. Cichlid fishes: behaviour, ecology and evolution, Chapman \& Hall, London. $378 \mathrm{pp}$.

Keenleyside, M.H.A. \& B.F. Bietz. 1981. The reproductive behaviour of Aequidens vittatus (Pisces, Cichlidae) in Surinam, South America. Env. Biol. Fish. 6: 87-94.

Kiener, A. 1963. Poissons, pêche et pisciculture à Madagascar. Publication Centre Technique Forestier Tropical 24. 244 pp.

Kiener, A. \& M. Maugé. 1966. Contribution à l'étude systématique et écologique des poissons Cichlidae endémiques de Madagascar. Mém. Mus. Natl. Hist. Nat. XL 2: 51-99.

Kraft, A. v. \& H.M. Peters. 1963. Vergleichende Studien über die Oogenese in der Gattung Tilapia (Cichlidae, Teleostei). Z. Zellforsch. 61: 434-485.

Kuwamura, T. 1986. Substratum spawning and biparental guarding of the tanganyikan cichlid Boulengerochromis microlepis with notes on its life history. Physiol. Ecol. Japan. 23: 31-43.

Lavery, R.J., R.W. Mackereth, D.R.C. Robillard \& M.H.A. Keenleyside. 1990. Factors determining parental preference of convict cichlid fry, Cichlasoma nigrofasciatum (Pisces, Cichlidae). Anim. Behav. 39: 573-581.

Loiselle, P.V. 1985. The cichlid aquarium. Tetra-Press, Melle. $287 \mathrm{pp}$.

Martin, P. \& P. Bateson, 1986. Measuring behaviour, an introductory guide. Cambridge University Press, Cambridge $200 \mathrm{pp}$.

Meyer, A., T.D. Kocher, P. Basasibwaki \& A.C. Wilson. 1990. Monophyletic origin of Lake Victoria cichlid fishes suggested by mitochondrial DNA sequences. Nature 347: 550-553.

Nagoshi, M. 1987. Survival of broods under parental care and parental roles in the cichlid fish, Lamprologus toae, in Lake Tanganyika. Jap. J. Ichthyol. 34: 71-75.

Noakes, D.L.G. \& E.K. Balon. 1982. Life histories of tilapias: an evolutionary perspective. pp. 61-82. In: R.S.V. Pullin \&
R.H. Lowe-McConnell (ed.) The Biology and Culture of Tiliapias, ICLARM Conference Proceedings 7, Manila.

Ostrander, G.K. \& J.A. Ward. 1985. The function of the pelvic fins during courtship and spawning in the orange chromide, Etroplus maculatus. Env. Biol. Fish. 13: 203-210.

Perrone, M. 1978. Mate size and breeding success in a monogamous cichlid fish. Env. Biol. Fish. 3: 193-201.

Perrone, M. \& T.M. 7aret. 1979. Parental care patterns of fishes. Amer. Nat. 113: 351-362.

Peters, H.M. \& S. Berns. 1982. Die Maulbrutpflege der Cichliden. Untersuchungen zur Evolution eines Verhaltensmusters. Z. zool. Syst. Evol. forsch. 20: 18-52.

Raminosoa, N.R. 1987. Écologie et biologie d'un poison téleostéen: Ophiocephalus striatus (Bloch, 1793), introduit à Madagascar. PhD thesis, University of Madagascar, Tananarive. 225 pp.

Rechten, C. 1980a. Brood relief behaviour of the cichlid fish Etroplus maculatus. Z. Tierpsychol. 52: 77-102.

Rechten, C. 1980b. A note on the reproductive colouration of the cichlid fish Etroplus maculatus. Z. Tierpsychol. 52: 135140.

Reinthal, P.N. \& M.L.J. Stiassny. 1991. The freshwater fishes of Madagascar: a study of an endangered fauna with recommendations for a conservation strategy. Cons. Biol. 5(2): 231-243

Robertson, D.R. 1973. Field observations on the reproductive behaviour of a pomacentrid fish, Acanthochromis polyacanthus. Z. Tierpsychol. 32: 319-324.

Shaw, L. 1971. Evidence of sexual maturation in young adult shiner perch, Cymatogaster aggregata Gibbons (Perciformes, Embiotocidae). Amer. Mus. Novit. 2479: 1-10.

Smith-Grayton, P.K. \& M.H.A. Keenleyside. 1978. Male-female parental roles in Heterotilapia multispinosa (Pisces, Cichlidae). Anim. Behav. 26: 520-526.

Stiassny, M.L.J. 1987. Cichlid familial relationships and the placement of the neotropical genus Cichla (Perciformes, Labroidei). J. Nat. Hist. 21: 1311-1331.

Stiassny, M.L.J. 1990a. Notes on the anatomy and relationships of the bedotiid fishes of Madagascar, with a taxonomic revision of the genus Rheocles. Amer. Mus. Novit. 2799: 1-33.

Stiassny, M.L.J. 1990b. Tylochromis, relationships and the phylogenetic status of the African Cichlidae. Amer. Mus. Novit. 2993: 1-14.

Stiassny, M.L.J. 1991. Phylogenetic intrarelationships of the family Cichlidae: an overview. pp. 1-35. In: M.H.A. Keenleyside (ed.) Cichlid Fishes: Behaviour, Ecology and Evolution, Chapman \& Hall, I ondon.

Stiassny, M.L.J. 1992. Phylogenetic analysis and the role of systematics in the biodiversity crisis. In: N. Eldredge (ed.) Systematics, Ecology, and the Biodiversity Crisis, Columbia University Press, New York (in press).

Stiassny, M.L.J. \& J.S. Jensen. 1987. Labroid intrarelationships revisited: morphological complexity, key innovations, and the study of comparative diversity. Bull. Mus. Comp. Zool. 151: 269-319.

Thys van den Audenaerde, D.F.E. 1968. A preliminary contri- 
bution to a systematic revision of the genus Pelmatochromis Hubrecht sensu lato (Pisces, Cichlidae). Rev. Zool. Bot. Afr. 77: 349-391.

Timms, A.M. \& M.H.A. Keenleyside. 1975. The reproductive behaviour of Aequidens paraguayensis (Pisces, Cichlidae), $Z$. Tierpsychol. 39: 8-23.

Ward, J.A. \& J.I. Samarakoon. 1981. Reproductive tactics of the Asian cichlids of the genus Etroplus in Sri Lanka. Env. Biol. Fish. 6: 95-103.
Wickler, W. 1956. Der Haftapparat einiger Cichliden Eier. Z. Zellforsch. 45: 304-327.

Wickler, W. 1967. Vergleich des Ablaichverhaltens ciniger paarbildender sowie nicht-paarbildender Pomacentriden und Cichliden (Pisces, Perciformes). Z. Tierpsychol. 24: 457-470. Zoran, M.J. \& J.A. Ward. 1983. Parental egg care behavior and fanning activity for the orange chromide, Etroplus maculatus. Env. Biol. Fish. 8: 301-310. 